\title{
Comments killed the k-pop star. Mord społeczny na Choi Jin Ri jako studium przypadku współczesnej paniki moralnej ${ }^{1}$
}

\author{
Comments killed the k-pop star: \\ Social murder of Choi Jin Ri \\ as the case study of contemporary \\ moral panic
}

DOI: $10.12775 /$ LL.2.2021.008 | CC BY-ND 3.0 PL

\begin{abstract}
The socially unacceptable behavior of Choi Jin Ri - known professionally as Sulli - resulted in a wave of moral panic which spread among the South Korea netizens. Anti-fans gathered around the artist after her transgressions against the unwritten rules of Korean pop culture industry - a sort of ethos regulating the behavior of idols and their relationships with fans. The conservative society rejected Choi Jin Ri's feminist ideas, her close relationship with other woman idols, and the sexual innuendo in the content she published on social media. This article constitutes a case study of the Internet and media hate, with particular emphasis on the way in which Internet users' comments and reactions to Choi Jin Ri's private life affected both the reception of her work and her mental health, which in consequence lead to the artist's suicide in 2019. The article discusses the issue of performative hate in the content published by South
\end{abstract}

1 Tytuł artykułu jest parafrazą tytułu piosenki Video Killed the Radio Star zespołu The Buggles z $1979 \mathrm{r}$. 
Korean Internet users by analyzing selected elements of contemporary media landscape - the pursuit of scandal, the increase in media voyeurism, and the loss of privacy among public figures resulting from attempts at satisfying the needs and curiosity of fans - as well as the moral panic mechanisms understood as a social phenomenon facilitated by the structure of contemporary media..

KEYWORDS: k-pop, moral panic, fandom, social media, social murder, Hallyu

\author{
Nazywam się Sulli. „Sul” oznacza śnieg, a „Li” kwiaty gruszy, \\ więc prawdopodobnie odrodze się jako kwiat - niewielki, \\ ale pełen witalności. \\ (Choi Jin Ri dla „InStyle Korea”, Marzec 2012)
}

Współczesny dyskurs medialny żywi się kontrowersjami, szczególnie związanymi z kulturą celebrycką, częściowo traktowaną jak źródło wzorców postępowania dla nastolatków i młodszych odbiorców, a częściowo jako źródło rozrywki na równi z fikcyjnymi treściami, jakie udostępnia przemysł kulturowy. Śledzenie zachowań wpływowych celebrytów staje się coraz łatwiejsze w obliczu postępującego zaniku prywatności. Za pomocą mediów społecznościowych gwiazdy pokazują dotychczas ukryte obszary swojego życia, co staje się nie tylko normą, ale wręcz nakazem w przemyśle rozrywkowym, nastawionym na podtrzymywanie relacji paraspołecznej i lojalności konsumentów. Zainteresowanie prywatnością celebrytów jest kulturowym przejawem ciekawości, która może jednak nasilać się i ostatecznie przerodzić w obsesję, zwaną voyeuryzmem mediów społecznościowych (ang. social media voyeur), czyli społecznie i kulturowo stymulowaną praktykę cyfrowego podglądactwa, która stanowi znaczną część aktywności wielu internautów (Sutherland Labs, 2015). Gwałtowne przemiany zachodzące w naszym krajobrazie medialnym pod względem zaniku prywatności oraz coraz częstsze przypadki wycieku wrażliwych informacji na nasz temat jako konsumentów i obywateli, stanowią podatny grunt dla wybuchu i podtrzymywania różnego rodzaju panik moralnych.

Termin „panika moralna” opisuje gwałtowny niepokój społeczny, spowodowany poczuciem zagrożenia wartości pielegnowanych przez daną grupę. Eric Goode i Nachman Ben-Yehuda wyróżniają pięć kryteriów definiujących przebieg paniki moralnej: zaniepokojenie, wrogość, konsensus, dysproporcję oraz nieprzewidywalność. Pierwszy czynnik oznacza wzrastającą obawę społeczeństwa spowodowaną zachowaniem osoby bądź grupy niestosującej się do powszechnie przyjętych norm. Zaniepokojenie wyrażane jest jawnie, za pomoca chociażby niepochlebnych komentarzy w mediach i sferze publicznej. Wrogość okazywana jest przez podział: „my”, czyli grupa chcąca zachować obecny porządek, kontra „oni”, złoczyńcy chcący go zburzyć. Konsensus oznacza, że doszło do osiągnięcia zgody odnośnie zaistnienia społecznego problemu i potrzeby podjęcia działań, aby go rozwiązać. Dysproporcja odnosi się do zastosowanych środków zaradczych, nieproporcjonalnych do rzeczywistej wagi problemu. 
Ostatnim kryterium jest nieprzewidywalność - nigdy nie wiadomo, w którą stronę podąży napędzany emocjami dyskurs i jakie będą jego społeczne konsekwencje. Może samoistnie zaniknąć lub stworzyć podwaliny dla nowej instytucji czy organizacji, czyli przerodzić się w działanie społeczne (Zielińska, 2004, s. 162-164). Im bardziej restrykcyjne ograniczenia norm społecznych i kulturowych, tym większe ryzyko przekroczenia lub podważenia obowiązujących zasad, co $\mathrm{w}$ połączeniu z medialnym voyeuryzmem i zanikiem prywatności osób publicznych sprawia, że celebryci stają się kozłami ofiarnymi w działaniach służących przyciąganiu i podtrzymywaniu uwagi odbiorców, uwidacznianiu niepisanych zasad i norm kulturowo-społecznych oraz prezentowaniu, co spotyka jednostki dokonujące różnego rodzaju transgresji.

Rynek rozrywkowy Korei Południowej charakteryzuje się szeregiem zawiłych zasad regulujących publiczne zachowanie gwiazd (idoli). Istnienie takich nieoficjalnych norm wyraźnie odróżnia azjatycki przemysł kulturowy od zachodniego, gdzie tego typu podejście nie występuje, co więcej, często wykorzystuje się skandal obyczajowy jako narzędzie reklamy. Zachodni dyskurs opiera się na pojęciu talentu, w Korei natomiast uważa się, że każdy aspekt związany z karierą muzyczną może zostać wyuczony. Wytwórnie zwracają uwagę nie tylko na umiejętności głosowe czy ruchowe, ale kładą duży nacisk na wygląd, a nawet narodowość potencjalnego członka lub członkini nowej grupy muzycznej. Większość koreańskich artystów nie bierze bezpośredniego udziału w procesie komponowania wykonywanej przez siebie muzyki. Zauważalną różnicą $\mathrm{w}$ stosunku do zachodniego modelu jest tworzenie kilku wersji językowych albumów; jest to zabieg wspierający ekspansję k-popu na rynki innych państw. Wydawnictwa zachodnich artystów są w przytłaczającej większości anglojęzyczne (Koreaboo, 2018b).

Inną uderzającą różnicą pomiędzy tymi rynkami jest bardzo krytyczny stosunek koreańskiej opinii publicznej do rodzimych artystów, których zachowanie podlega nieustannej ocenie moralnej. Ten system ewaluacji idoli podtrzymywany jest przez wytwórnie i koncerny medialne, które zobowiązują zakontraktowanych muzyków do przestrzegania szeregu zasad związanych z szeroko rozumianą obyczajowością. Przykładowo, przebywanie w towarzystwie osoby innej płci, budowanie relacji romantycznych czy odejście od restrykcyjnej diety może zostać uznane za poważne wykroczenie i być powodem do publicznej dyskredytacji idola w oczach fanów i przedstawicieli przemysłu muzycznego (Grazy Grace, 2018). Najłagodniejszym wymiarem kary jest zmuszenie do publicznych przeprosin gwiazdy, która dokonała transgresji. Musi się ona pojawić w kilku programach rozrywkowych, gdzie okazuje skruchę za nieprzestrzeganie zasad. W bardziej radykalnym i częściej wybieranym wariancie kary artysta zostaje wpisany na „czarną listę”, która skutecznie uniemożliwia mu powrót do koreańskiej czołówki znanych i lubianych piosenkarzy, a on sam staje się czymś w rodzaju przykrego wspomnienia. Wytwórnie nie mogą pozwolić sobie na trzymanie w swoich szeregach problematycznych osób, dlatego nie mają większych oporów przed usunięciem niewygodnych pracowników. Chociaż dla za- 
chodniego odbiorcy może to wydawać się okrutnym działaniem, jeszcze w zeszłym stuleciu amerykański przemysł filmowy w podobny sposób pozbywał się swoich gwiazd. Przykładowo, Bobby Driscoll został zwolniony z wytwórni Disneya w 1953 r., w wieku 11 lat. Powodem nagłego rozwiązania kontraktu było gwałtowne przechodzenie okresu dojrzewania przez nastolatka. Ostatecznie Driscoll, zapomniany i bezdomny, zmarł w 1968 r. po przedawkowaniu narkotyków (Rice, 2019). Wytwórnia Disneya po dziś dzień nakłada na swoje małoletnie gwiazdy obyczajowe restrykcje, wywierając na nie nieustanną presję, co owocuje nie tylko licznymi skandalami, ale też życiowymi problemami wielu promowanych przez wytwórnię solistów i zespołów.

To, co mogłoby zostać złagodzone przez PR-owe działania na Zachodzie, w Korei Południowej jest podsycane przez działalność internautów. Koreańscy netizeni uwielbiają pisać komentarze na portalach plotkarskich, udzielać się na forach czy komentować zdjęcia zamieszczane przez idoli w mediach społecznościowych. Fani (czy też anty-fani) szczególnie upodobali sobie wyrażanie niepochlebnych i często krzywdzących komentarzy. Warto też zauważyć, że to właśnie Koreańczycy przodują w hejcie wobec przedstawicieli rodzimego showbiznesu ${ }^{2}$. Globalna wspólnota fanowska jest znacznie bardziej wyrozumiała wobec przewinień idoli niż rodzimi fani. Wielokrotnie też członkowie fandomów z różnych zakątków świata protestowali przeciwko południowokoreańskiej krytyce, którą odbierali jako niewspółmierną do wykroczenia lub wręcz nieuzasadnioną (yuryuni, 2015). Jedną z ofiar bezrefleksyjnych komentarzy netizenów stała się młoda artystka, Choi Jin Ri, znana jako Sulli. Wokalistka ta zdobyła sławę dzięki występom w k-popowym zespole $\mathrm{f}(\mathrm{x})$. Mimo sukcesów międzynarodowych i zakończenia kariery muzycznej w grupie, nienawiść anty-fanów i ich ciągła obecność w jej życiu w formie cyberprzemocy i presji społecznej wpłynęła na problemy psychiczne artystki. Cierpiąca na depresję Sulli ostatecznie popełniła samobójstwo w 2019 r.

Niniejszy artykuł ma na celu przeanalizowanie wypadków, które doprowadziły do tragicznej śmierci artystki, w kontekście przemian we współczesnym krajobrazie medialnym. Takie zjawiska jak zanik prywatności (voyeuryzm medialny) oraz wzrost cyberprzemocy (szczególnie stalking, doxxing i hejt) stanowią integralny element mechanizmu paniki moralnej w dobie kultury cyfrowej, co jasno ilustruje przypadek nagonki, której ofiara padła Sulli. Ze względu na cyfrowy i medialny charakter tych prześladowań zostały one dokładnie udokumentowane, co pozwala krok po kroku prześledzić powstanie, rozwój i narastanie paniki moralnej. Jednocześnie warto zwrócić uwagę na fakt, że omawiane tu negatywne

2 W swoich rozważaniach przyjmuję, że hejt „to forma dewiacyjnych zachowań podczas publicznych dyskusji internetowych. Polega ono na używaniu obelżywego języka, pogardliwej ocenie różnych zjawisk, znieważaniu zarówno rozmówców, jak i różnych innych podmiotów oraz na wyrażaniu agresji i nienawiści pod ich adresem. Hejterskie komentarze nie niosą ze sobą żadnej merytorycznej treści ani nie wnoszą do dyskusji niczego poza agresją ukierunkowaną na inne osoby bądź grupy” (Juza, 2015, s. 29). 
i szkodliwe zjawiska medialne nie są jakąś anomalią (nie tylko na tle koreańskiego przemysłu muzycznego, ale w ujęciu globalnym), ale wydają się wręcz symptomatyczne dla scyfryzowanej współczesności, a Sulli jest jedną z wielu ofiar internetowej i medialnej przemocy.

Od ponad dekady świat zalewa tzw. koreańska fala. Termin ten, oryginalnie brzmiący Hallyu Wave, ukuty został przez chińską prasę w latach 9o. XX w. Oznacza on ogromną popularność koreańskiej popkultury, głównie mini-seriali. Obecnie najsłynniejszym towarem eksportowym Korei Południowej stała się muzyka, zbiorczo nazywana k-popem. Ponieważ istotnym kontekstem dla dalszych rozważań jest koreański przemysł kulturowy, należy w skrócie przybliżyć, jak wygląda jego specyfika w odniesieniu do sektora muzycznego.

Południowokoreańscy idole wybierani są w swego rodzaju castingach spośród tysięcy chętnych, nie tylko Koreańczyków, ale też Chińczyków, Japończyków, Tajów czy dzieci koreańskich emigrantów ze Stanów Zjednoczonych lub Australii. Wytwórnie muzyczne poszukują nowych talentów podczas specjalnych wydarzeń organizowanych w największych koreańskich miastach, poza granicami kraju lub w formie audycji online (Upadhyay, 2021). Pomyślne przejście pierwszej selekcji stanowi dopiero wstęp do kariery, później bowiem zaczynają się mordercze przygotowania do debiutu, który zresztą może nigdy nie nadejść. Trainee, jak nazywa się młodych adeptów k-popu, porzucają domy i bliskich, aby przeprowadzić się do kontrolowanego przez wytwórnię kampusu, gdzie przechodzą intensywny trening, mający zbliżyć ich do zrealizowania marzenia o sławie (Womack, 2021). Jest to niewątpliwie trudna sytuacja dla trainee, tym bardziej, że na audycje zgłaszają się osoby niepełnoletnie, a często nawet dzieci (Womack, 2021). Częścią wieloletniego szkolenia jest podporządkowanie się panującym wśród idoli zasadom, m.in. zakazom bliższych kontaktów z płcią przeciwną, prowadzenia profili w mediach społecznościowych, uczestniczenia w hucznych imprezach i korzystania z jakichkolwiek używek (Seoulspace, 2021a; Womack, 2021). Zajęcia prowadzone przez wytwórnie składają się z treningu wokalnego, tanecznego, nauki języków, nauki radzenia sobie $\mathrm{z}$ mediami i fanami (Leung, 2012; Seabrook, 2012). Dzień treningowy trwa standardowo około dziesięciu godzin, jednak dobrze widziane jest spędzanie większej ilości czasu na doskonaleniu techniki śpiewu i ruchu (Koreaboo, 2020). W napiętym grafiku trainee brakuje miejsca na edukację i życie towarzyskie, dlatego wielu adeptów całkowicie rezygnuje z typowych doświadczeń nastolatka, skupiając się na unikalnej szansie zrobienia kariery (Peycheva, 2012). Trainee stosuja restrykcyjne diety, aby podczas debiutu wyglądać perfekcyjnie (Seoulspace, 2021a). Wielu marzących o karierze muzycznej poddaje się także operacjom plastycznym, aby sprostać koreańskiemu ideałowi piękna, na który składa się pięć głównych cech: mała twarz, jasna skóra, niewielki nos, duże oczy oraz szczupła sylwetka (Seoulspace, 2021b). W ciagu ostatnich lat trend ten zaczął powoli jednak ustępować, a twarze idoli stają się coraz bardziej zróżnicowane (Moreau, 2020). Trainee co miesiąc przechodzą test umiejętności (ang. monthly evaluation test), polegający na tym, że zarząd wytwórni sprawdza czynione 
przez nich postępy. Dyrektorzy przydzielają aspirujących idoli do grup, które muszą przygotować występ w stylu danego konceptu³. Co ważne, trainee nie przygotowują się do debiutu za darmo - szkolenia, diety i zabiegi medycyny plastycznej są płatne. Wytwórnie prowadzą przez ten okres ewidencję wydatków składających się na formę kretytu, który musi zostać spłacony. Spłata owego długu pochłania większość zarobionych później pieniędzy, w związku z czym wielu idoli przez część swojej kariery nie zarabia, chociaż generuje zyski (Koreaboo, 2018a). Zapisy dotyczące tego aspektu są częścią podpisywanego tzw. niewolniczego kontraktu (Williamson, 2011). Jedynie topowe wytwórnie SM Entertainment, YG Entertainment, JYP Entertainment - nie żądają spłaty długu i pozwalają swoim artystom zarabiać od początku kariery (SBS PopAsia HQ, 2018). Dopiero od 2017 r. na skutek nacisków ze strony rządu i zmiany regulacji prawnych wytwórnie nie mogą zmuszać do uregulowania należności tych osób, które nie zadebiutowały (Gonsalves, 2020). Wielu przygotowujących się do debiutu nie jest $\mathrm{w}$ stanie znieść presji bądź złego traktowania, przez co rezygnują z marzeń o sławie. Okres bycia trainee trwa zazwyczaj około pięciu lat, ale może przedłużyć się nawet do piętnastu (Do, 2015). Kiedy wreszcie dochodzi do upragnionego debiutu, artystom nie zawsze udaje się utrzymać w „pierwszej lidze” koreańskich piosenkarzy.

Kariera idola nie trwa długo. Aktualnie regulacje prawne nie pozwalają na zawieranie umów dłuższych niż siedem lat (Korea Times, 2020)4 ${ }^{4}$, podpisując zatem kontrakt jako nastolatkowie, potencjalni idole kończą swoje kariery i przechodzą na artystyczną „emeryturę" mając około 25 lat. Po upływie czasu trwania umowy artyści muszą zdecydować, czy chcą pozostać częścią koreańskiego przemysłu rozrywkowego, czy też wolą spróbować swoich sił w innej branży. Wybierając pierwszą opcję, mogą - w zależności od popularności ich grupy - przedłużyć swoje kontrakty w wytwórni, gdzie kontynuują aktywność jako zespół, lub rozwijać solowe kariery. Wielu z nich decyduje się na podpisanie nowej umowy z inną agencją (Dong, 2020). Dla idoli kariera solowa lub aktorska jest naturalnym przedłużeniem pracy, a wielu koreańskich celebrytów próbuje swoich sił na tych polach jeszcze w trakcie aktywności grupowych (Hazra, 2021; kpopStarz, 2020). Podejmowane decyzje związane są z ambicjami artystów, ale wybór dalszej kariery warunkowany jest również tym, że znają już oni schematy działania przemysłu rozrywkowego w Korei Południowej, czują się więc w tej branży względnie bezpiecznie (Dong, 2020). Niektórzy idole decydują się na działalność $\mathrm{w}$ internecie i prowadzenie w serwisie YouTube kanałów o różnorodnej tematyce

3 Koncept (ang. concept) to motyw przewodni danego utworu, zarówno muzyczny, jak i wizualny. Niektóre z południowokoreańskich grup posiadają swój koncept grupowy. Najpopularniejsze koncepty istniejące w k-popie nawiązują m.in. do stylu szkolnego (noszenie strojów przypominających mundurki; BTS podczas promocji Boy In Luv), futuryzmu (aespa - Next Level), wakacji (Twice - Dance The Night Away), literatury (IU - The Red Shoes), elementów nadprzyrodzonych (Dreamcatcher - Chase Me). 
(Tan, 2019). Część celebrytów zakłada własne agencje, aby zyskać większą autonomię (Dela Cruz, 2020). Jednak nie wszyscy chcą pozostawać w obrębie przemysłu rozrywkowego, dlatego niektórzy po zakończeniu kontraktu decydują się na całkowitą zmianę sojego życia zawodowego (Koreaboo, 2018c).

Sulli należała do crème de la crème k-popowego świata. Zespół $\mathrm{f}(\mathrm{x})$ zyskiwał popularność dzięki artystycznej różnorodności wyrażającej się także poprzez jego międzynarodowy skład, w którym znalazła się Krystal, Koreanka wychowana w Stanach Zjednoczonych, Amber, Amerykanka tajskiego pochodzenia, oraz Victoria, rodowita Chinka. Grupa zdobyła również rozgłos dzięki wizualnemu zerwaniu ze schematem wyłącznie pięknych, delikatnych dziewcząt jedna z członkiń była stylizowana na chłopczycę. W podsumowaniu Billboardu drugi album $\mathrm{f}(\mathrm{x})$, Pink Tape, został uznany za najlepszy album k-popowy wydany w latach 2010-2019 (Billboard Staff, 2019).

Sulli przeszła drogę znacznie dłuższą niż większość południowokoreańskich artystów. Karierę rozpoczęła już jako dziecięca aktorka w wieku 11 lat. Niedługo potem zaczęła trenować, by ostatecznie zadebiutować z grupą w 2009 r. Po pięciu latach występowania $\mathrm{w} f(\mathrm{x})$ i grania w serialach, wytwórnia SM Entertainment ogłosiła, że Sulli robi przerwę w występach. Powodem decyzji miało być wyczerpanie spowodowane negatywnymi komentarzami skierowanymi w jej stronę. Wcześniej Choi Jin Ri była hospitalizowana z powodu nerwobóli. Wokół sytuacji zaczęły narastać plotki dotyczące potajemnych randek idolki z Choizą, raperem stanowiącym część formacji Dynamic Duo (Jones, 2014). Było to złamanie jednej z zasad obowiązujących każdego południowokoreańskiego idola - absolutny zakaz wchodzenia w związki czy nawet posiadania jakiejkolwiek relacji z przedstawicielem płci przeciwnej - dla fana-Koreańczyka wokalistka takiego zespołu jak $\mathrm{f}(\mathrm{x})$ musi pozostać nieskalanym seksualnie wzorem postępowania. Na domiar złego, rzekomy wybranek gwiazdy był od niej o 14 lat starszy, co według południowokoreańskiego społeczeństwa jest nieodpowiednie (Benjamin, 2019). Niedługo potem zaczęto mówić o domniemanej ciąży Sulli, którą sfotografowano w szpitalu, tuż po wyjściu z gabinetu ginekologicznego (J.K., 2019). Sytuacja ta dała pretekst do wzmożonych ataków na Choi Jin Ri. Skoro bowiem potajemny związek spotkał się z taką dezaprobatą, to plotka o ciąży młodej artystki musiała rozwścieczyć fanów. W $2015 \mathrm{r}$. Sulli opuściła swoją grupę, by skupić się na aktorstwie; wtedy też oficjalnie potwierdzono, że spotyka się ze wspomnianym Choizą (Kim, 2015). Związek ten spowodował, że gwiazda została ofiarą ostracyzmu ze strony show-biznesu. Nie mogła już prowadzić działalności konferansjerskiej ze względu na „złą sławe”, która zniechęcałaby widzów do oglądania programu. Dopiero w 2018 r. to „embargo" zostało uchylone i Sulli wystąpiła jako jedna z czterech prowadzących program na antenie stacji JTBC (Hong, 2019). Wcześniej został też wyemitowany reality show z jej udziałem. Odejście gwiazdy z zespołu wywołało również falę nienawiści wśród dotychczas wiernych jej fanów. Wielu wielbicieli Choi Jin Ri zaczęło pisać niewybredne posty czy tweety na temat jej stosunku do obowiązków członkini zespołu $\mathrm{f}(\mathrm{x})$, w tym niechęci do pozostałych wokalistek. 
Główną prowodyrką owego hejtu była Jinnabit, niegdyś administratorka największej strony zrzeszającej fanów Sulli, która w serii tweetów zarzucała koreańskiej celebrytce niedojrzałość, zgrywanie ofiary i sabotowanie działań grupy (Haxoru, 2015).

Prawdziwą kopalnią materiałów wykorzystywanych do znieważenia Choi Jin Ri był jej Instagram. Jedno z kont wokalistki zostało otwarte w 2015 r. W czasie używania tego profilu, Sulli co najmniej dwukrotnie padła ofiarą ataków hakerskich (Sayuridoll, 2016). Fani niejednokrotnie korzystali z opcji komentarza, aby dać upust swoim negatywnym emocjom wobec artystki. Nie chodziło im już tylko o rozgoryczenie spowodowane odejściem z zespołu, ale też o treści udostępniane przez celebrytkę. Zdjęcia zamieszczane przez Choi Jin Ri wydawały się im seksualnie sugestywne, a sama gwiazda miała według nich upodabniać się do lolity ${ }^{5}$. Oskarżenia te wywołała sensualna sesja zdjęciowa Rotty, który zasłynął wykonywaniem fotografii przedstawiających idolki w dwuznacznych pozach (Dong, 2018). Na zdjęciach, oprócz Sulli, pojawiła się też Goo Ha Ra, jej wieloletnia przyjaciółka. Fotografia przedstawiająca stojące przy sobie idolki przykryte wyłącznie ogromną koszulką z logo oliwki Johnson’s Baby rozjuszyła netizenów. Wśród fanów rozgorzała dyskusja na temat tego, czy działania Sulli są odważne, czy jednak daje ona zły przykład. Jedni uważali, że Sulli, robiąc z siebie obiekt seksualny i umieszczając fotografie w internecie, zachowuje się nieodpowiednio, godząc się na swoje uprzedmiotowienie. Inni z kolei twierdzili, że publikując takie zdjęcia, gwiazda dokonuje seksualnej autoekspresji, czym wpisuje się w postulaty trzeciej fali feminizmu. Działania te były też uważane za przejaw buntu wobec wizerunku narzuconego Choi Jin Ri przez wytwórnię (Mark, 2017). Warto zauważyć, że o ile tego typu fotografie wzbudzają kontrowersje, to już same występy idolek w krótkich spódniczkach, sukienkach czy mundurkach z szortami bezpieczeństwa (ang. safetyshorts) ${ }^{6}$, wzbogacone przesiąkniętą erotyzmem choreografią i bardzo sugestywną pracą kamery nie sprawiają nikomu problemu. Nikt nie zwrócił uwagi na ten podwójny standard i na osobliwe relacje pomiędzy wizerunkiem gwiazdy uznanym za kontrowersyjny, a standardowym wizerunkiem kreowanym przez przemysł muzyczny.

Stosunki Choi Jin Ri z innymi gwiazdami, a dokładniej sposoby, w jakie były one przedstawiane, również wywoływały powszechne oburzenie. Jednym

5 Termin „lolita” jest eponimem oznaczającym przedwcześnie dojrzałą seksualnie dziewczynkę. W ujęciu azjatyckim ma dwa znaczenia. Pierwsze to przedstawianie niepełnoletniej idolki jako obiektu seksualnego przez określone zachowania, pozy, sposób mówienia, sugestywny układ taneczny oraz ubiór. Drugie oznacza pełnoletnią osobę publiczną, którą celowo stylizuje się tak, aby przypominała lolitę w pierwszym znaczeniu. W tym przypadku cechami charakterystycznymi są przypisywane dziewczynkom części garderoby, dziecięce uczesania (takie jak podwójny kucyk), niewinny, chociaż nacechowany erotyczne wyraz twarzy itd.

6 Ze względu na panujący w Korei Południowej kanon piękna, nogi artystek muszą zostać optycznie wydłużone przez noszenie jak najkrótszych szortów, spódniczek lub sukienek. „Szorty bezpieczeństwa” to element garderoby noszony przez koreańskie idolki, mający zapobiegać przypadkowemu pokazaniu intymnych części ciała podczas wykonywania choreografii lub zasłaniający ewentualne wady kostiumów scenicznych. 
z przykładów tej tendencji może być obszernie dokumentowana w mediach społecznościowych piżamowa impreza Sulli i Goo Ha Ra, podczas której doszło do pocałunku między kobietami. Netizeni zaczęli wypisywać homofobiczne komentarze pod adresem celebrytek. Ze względu na panującą w Korei Południowej homofobię niewiele osób z tamtejszego środowiska showbiznesu pozwala sobie na otwarte wyrażanie swojej odmiennej orientacji seksualnej. Głównym powodem jest strach przed utratą fanów, a co za tym idzie, pracy i źródła utrzymania. Mimo braku deklaracji na temat tożsamości seksualnej ze strony Sulli, wokalista spotkała się z ogromną krytyką za pokazanie się w tak dwuznacznej scenie.

Drugą sytuacją, która przysporzyła kłopotów Choi Jin Ri, było oznaczenie G-Dragona - jednego z najsłynniejszych koreańskich idoli, członka zespołu BIGBANG - na zdjęciu udostępnionym na Instagramie. Problem polegał na tym, że na fotografii celebrytka oznaczyła nie tylko oficjalny profil Kang Ji Yonga (prawdziwe imię G-Dragona), ale również jego profil prywatny, przeznaczony wyłącznie dla bliskich mu osób. Mimo przyjaźni łączącej Sulli z męską gwiazdą k-popu, Koreańczycy uznali to za próbe ponownego przebicia się skandalistki do „pierwszej ligi” rodzimego show-biznesu. W niepochlebnych komentarzach zarzucano Choi Jin Ri wykorzystywanie znajomości z dużo popularniejszym od niej muzykiem, głupotę i chorobę psychiczną (Koreaboo, 2018d).

Innym problemem dla koreańskiej społeczności fanów była niechęć Sulli do noszenia biustonosza. Sprawa urosła do takich rozmiarów, że postanowiono ją sparodiować w lokalnej wersji Saturday Night Live (Lee, 2016). Choi Jin Ri, odkąd zerwała $\mathrm{z}$ wizerunkiem idolki, często dzieliła się ze światem zdjęciami, na których pod ubraniem widoczne były jej sutki. Uważała się za część południowokoreańskiego no bra movement, w którym brak stanika oznaczał sprzeciw wobec powszechnego oceniania kobiecego ciała i wyśrubowanych standardów urody. Za każdym razem gdy na jej instagramowym profilu pojawiało się zdjęcie $\mathrm{z}$ widocznym brakiem tej części garderoby, celebrytka spotykała się ze wzmożonym hejtem. Wiele osób zgłaszało też te fotografie do usunięcia, uważając je za niestosowne. Oburzenie wyrażano także w komentarzach (Wamxiang, 2018). Choi Jin Ri nazywano osobą brudną, żebrzącą o atencję, a nawet proponowano jej przeprowadzkę do Ameryki. W większości popularnych komentarzy pokazywano ponadto, jak bardzo rodacy nie tolerują obranego przez nią stylu bycia. Każde nowe zdjęcie wstawianie na Instagram Sulli inspirowało przynajmniej kilka artykułów, w których dziennikarze rozpisywali się o braku bielizny i prezentowali fanowskie komentarze na ten temat. Warto zauważyć, że podobnie jak na Zachodzie, również w Korei Południowej nikt nie ma problemu z widocznymi męskimi sutkami (Epstein \& Joo, 2012). Sulli głośno popierała także akcję walki z ubóstwem menstruacyjnym, propagującą dostęp do artykułów higienicznych dla osób w trudnej sytuacji życiowej. Prototypy zaprojektowanych przez nią produktów zostały rozdane fanom niezależnie od ich płci. Artystka popierała także utworzenie tzw. „różowych skrzynek” (Hong, 2019a).

Powyższe wydarzenia można wpisać w przywołane wcześniej kryteria definiujące panikę moralną. Nieoficjalne powody odejścia Choi Jin Ri z zespołu 
wywołały niepokój społeczny, stwarzając pole do spekulacji i krytyki. Nieprzychylne komentarze pokazywały nastroje społeczne - początkowe zaniepokojenie stanem idolki zmieniało się w otwartą wrogość wobec niej. Z każdym jej kolejnym działaniem, które odbiegało od wartości i postaw reprezentowanych przez koreańskie gwiazdy, odzew opinii społecznej stawał się coraz bardziej radykalny. Nikt nie zwracał uwagi na to, że Choi Jin Ri nie była już idolką, więc owe zasady nie powinny jej obowiązywać. Społeczeństwo nadal postrzegało ją jak jedną z k-popowych gwiazd, dlatego oburzenie narastało. Fani wymagający od swoich ulubieńców ścisłego przestrzegania reguł odwrócili się od niej lub nadal obserwowali jej media społecznościowe, aby podkreślać, jak bardzo nie zasługuje na sławę czy zainteresowanie. Hejt wylewał się na Sulli z każdego możliwego powodu. W komentarzach ustanawiano jasny podział na dobre i „normalne” społeczeństwo oraz „wyzwoloną, nieodpowiedzialną, głupią” Choi Jin Ri. Można stwierdzić, że z każdym kolejnym wpisem i artykułem rósł konsensus co do tego, że celebrytka ze swoimi pomysłami, takimi jak brak biustonosza, seksualna sprawczość i walka z ubóstwem menstruacyjnym, mogła namieszać młodym Koreańczykom w głowach. Nie podobało się to konserwatystom broniącym zastanego porządku. W dyskusję włączyły się media, które z internetowych debat wybierały najbardziej obraźliwe opinie dotyczące postępowania Sulli, prezentując je następnie w szerszym obiegu. Analiza tworzonych w ten sposób materiałów pokazuje, że dyskurs medialny na temat autokreacji Choi Jin Ri jest nieadekwatny w stosunku do jej rzeczywistego wpływu na życie Koreańczyków. Brak stanika u jednej młodej, sławnej osoby nie może wszak zmienić poglądów całego społeczeństwa, a udział w sesji zdjęciowej nie powinien być aż tak szeroko komentowany, tym bardziej że wiele osób publikuje w sieci swoje półnagie zdjęcia.

Choi Jin Ri wielokrotnie apelowała do fanów o zaprzestanie hejtu, zarówno $\mathrm{w}$ trakcie występu $\mathrm{w}$ programie poświęconym negatywnym aspektom internetu, jak i poprzez transmisje na żywo na Instagramie. Mimo próśb o reakcję na akty cyfrowej agresji, skierowanych do SM Entertainment, Sulli nie otrzymała z ich strony wystarczającej pomocy. Agencja swoją opieszałość tłumaczyła problemami z namierzeniem adresów IP spoza Korei (Knetizen, 2019).

14 października 2019 r. Choi Jin Ri znaleziono martwą w jej domu. Uderzające jest to, że w obliczu tej tragedii niechętni artystce koreańscy internauci dalej wyrażali na jej temat negatywne opinie, twierdząc, że zdecydowała się na ten krok zbyt późno. Aby zneutralizować tego typu treści, w internecie rozpoczęto akcje „Love You, Sulli”, polegającą na masowym publikowaniu postów pełnych sympatii i szacunku do zmarłej, które miały sprawić, że wpisy zawierające hejt staną się mniej widoczne. O tragicznym końcu historii młodej Koreanki rozpisywały się media na całym świecie, zwracając uwage na jej zmagania z depresją i wrogością netizenów. Irlandzki zespół U2 podczas koncertu w Seulu uhonorował Sulli, uznając ją za jedną z osób, które mogą zmienić lub zmieniły sytuację kobiet w Korei Południowej (Hong, 2019b). 
Śmierć Choi Jin Ri rozpoczęła ogólnonarodową dyskusję na temat tego, jak daleko można posunąć się w wyrażaniu swojej opinii w internecie i jak krzywdzące jest publikowanie negatywnych komentarzy na temat drugiej osoby. Niektóre agencje wyciągnęły wnioski z tragicznego wydarzenia i podjęły kroki w celu lepszej ochrony swoich artystów przed internetowym hejtem. Jedną z firm, które zdecydowały się na zaostrzenie metod walki z negatywnymi treściami zamieszczanymi w sieci, jest KakaoM, opiekujące się bliską przyjaciółką Sulli, Lee Ji Eun, artystką znaną pod pseudonimem IU (Yeo, 2019).

Należy dodać, że wspomniana wcześniej Goo Ha Ra miesiąc po śmierci Choi Jin Ri również popełniła samobójstwo. W tej sytuacji koreańskie społeczeństwo skierowało do prezydenta liczne petycje o surowsze kary dla internetowych prześladowców, co znalazło swój finał w parlamencie. W październiku $2019 \mathrm{r}$. zaproponowano poprawkę do aktualnych przepisów, zobowiązującą firmy zarządzające serwisami komunikacyjnymi i informacyjnymi do usuwania agresywnych komentarzy. Poprawka nazywana potocznie „prawem Sull” (Sulli's Act) miała zostać przedyskutowana przed Zgromadzeniem Narodowym na początku grudnia 2019 r., jednak nie zyskała wystarczającego poparcia i ostatecznie nie stała się przedmiotem debaty (J.K., 2020), tym niemniej politycy nazywali śmierć Sulli mordem społecznym (Lim, 2019).

Pojęcie to zostało stworzone przez Friedricha Engelsa w 1845 r. Według filozofa, mord społeczny to stworzenie klasie robotniczej niekorzystnych warunków (mieszkaniowych, ekonomicznych, ekologicznych itd.), prowadzące w konsekwencji do wyższej śmiertelności i krótszego życia przedstawicieli owej klasy. Warunki te są świadomie kreowane przez wyższe warstwy jako element kontroli społecznej (Chernomas \& Hudson, 2009, s. 107). Użycie terminu „mord społeczny” w odniesieniu do sytuacji Choi Jin Ri zyskuje jednak nowy wymiar. W tym przypadku bowiem to niższa klasa (przynajmniej w klasycznym ujęciu ekonomicznym), czyli anonimowi netizeni Korei Południowej, stworzyli niekorzystne warunki (niesprzyjające środowisko cyfrowo-społeczne), które doprowadziły do samobójstwa artystki, przedstawicielki klasy wyższej. Hejterska nagonka wpłynęła bezpośrednio nie tylko na samopoczucie zmagającej się z problemami psychicznymi piosenkarki, ale też pozbawiła ją możliwości zarobkowania.

Analiza opisywanego w niniejszym artykule przypadku pozwala sformułować kilka wniosków i spostrzeżeń o bardziej ogólnym charakterze. Biorąc pod uwage sposoby działania współczesnego przemysłu rozrywkowego w Korei, należy stwierdzić, że to fani stają się tu siłą nadrzędną, która decyduje o statusie gwiazdy. To bowiem od pozyskania ich sympatii (a także względów szeroko pojętej opinii publicznej i dyskursu medialnego) zależy sukces artystyczny i ekonomiczny celebryty. Popularność idola, wielkość jego fandomu, przekłada się bezpośrednio na lukratywne kontrakty i status w koreańskiej popkulturze. Dzięki tej mocy fandom może też wydawać sądy na temat wybranych aspektów życia prywatnego celebryty. Fani decyduja, czy celebrytka może wejść w oficjalny związek z drugą osobą, oceniają jej wygląd, sposób okazywania uczuć, stopień 
poufałości w kontaktach $\mathrm{z}$ innymi, poglądy polityczne i społeczne zaangażowanie. Powszechnie praktykowany voyeuryzm medialny kreuje normy, do których sławna persona musi się dostosować. Nieprzychylne komentarze i artykuły z niezweryfikowanymi informacjami tworzą warunki zezwalające i zachęcające do obrażania i krytykowania uwielbianych wcześniej artystów. W takiej sytuacji rodzi się swoiste sieciowe środowisko nieustannego podglądactwa, oceniania i oczerniania, które jest legitymizowane przez masowe działania anty-fanów stanowiących dla siebie nawzajem moralny punkt odniesienia, usprawiedliwiający radykalne słowa i postawy (podejmowane także poza środowiskiem cyfrowym, np. stalkowanie artystki). Panika moralna napędza dalsze działania voyeurystyczne, które z kolei na zasadzie sprzężenia zwrotnego dostarczają kolejnych materiałów dla siejących i podtrzymujących ową panikę mediów. Te ostatnie wykorzystują nawet błahe lub niezweryfikowane informacje, aby formułować dalsze zarzuty pod adresem takich osób jak Sulli. Demokratyczny mecenat rynku zmienia się w dyktaturę, która nie toleruje niesubordynacji.

Chociaż sytuacja koreańskich idoli i narzucone im odgórnie ograniczenia zostały w ostatnich latach złagodzone lub usunięte, presja społeczeństwa odnośnie zachowania status quo nie pozwala, aby większość $\mathrm{z}$ owych formalnych rozwiązań została wcielona w życie. Choi Jin Ri była ofiarą przemysłu kulturowego - systemu, który daje ciche przyzwolenie na niszczenie ludzkiego życia w imię oglądalności i „klikalności”. Powszechny w Korei Południowej medialny voyeuryzm znacząco wpływał na poziom wyświetleń artykułów dotyczących Sulli, a zarazem przyczyniał się do szerzenia nieprawdziwych informacji na jej temat. Brak weryfikacji szokujących treści doprowadził do pogłębienia społecznej niechęci w stosunku do celebrytki (Borowiec, 2019). Działania podejmowane przez idolkę były zbyt odmienne od przyjętych norm regulujących zachowanie zarówno przedstawicieli przemysłu rozrywkowego, jak i całego społeczeństwa. Przypadek Sulli może być przy tym rozpatrywany w kategoriach mechanizmu kozła ofiarnego, koreańska opinia publiczna uznała ją bowiem za źródło społecznego zgorszenia związanego z przemianami obyczajowymi we współczesnej Korei. W takim ujęciu śmierć idolki jawi się więc jako swoiste oczyszczenie zbiorowości narażonej na obyczajowe zepsucie (Girard, 1987, s. 56). Błędem byłoby jednak sądzić, że Sulli to przypadek szczególny lub jedyna osoba pokrzywdzona w taki sposób. Przeciwnie, niemal każda formacja istniejąca w koreańskim przemyśle muzycznym staje się celem hejtu, czego idealnym przykładem jest Jennie Kim z grupy BLACKPINK, którą netizeni prześladują ze względu na jej domniemaną, „uprzywilejowaną” pozycję względem reszty członkiń zespołu (Lin, 2019).

Podsumowując niniejsze rozważania, warto zauważyć, że choć od śmierci Choi Jin Ri nie minęło jeszcze wiele czasu, machina koreańskiego przemysłu rozrywkowego, zalana kolejnymi debiutami, zdążyła już o niej zapomnieć. W tym kontekście widać wyraźnie, że kolorowe teledyski i chwytliwe melodie, które serwuje światu k-pop, przysłaniają fanom ciemniejszą stronę życia artystów, kierując uwagę jedynie na ich sceniczny wizerunek. 


\section{BIBLIOGRAFIA}

Benjamin, J. (2019). Sulli Was an Outspoken K-Pop Star in an Industry That Would've Preffered She Stayed Quiet. Retrieved from: https://www.billboard.com/articles/columns/ktown/8532906/sulli-legacy-memorial-outspoken-kpop-star

Billboard Staff. (2019). 25 Greatest K-Pop Albums of the 2010s: Staff List. Retrieved from: https:// www.billboard.com/articles/columns/k-town/8546586/greatest-k-pop-albums-201os-top-25

Borowiec, S. (2019). Commentary: Who really killed South Korean celebrity Sulli? Retrieved from: https://www.channelnewsasia.com/news/commentary/south-korea-celebrity-sulli-f-x-suicide-cause-death-12018318

Chernomas, R., \& Hudson, I. (2009). Social Murder: The Long-Term Effects of Conservative Economy Politcs. International Journal of Health Services, 39(1), 107-121. doi: 10.2190/HS.39.1.e

Dela Cruz, E. (2020). These Successful K-pop Idols Also Own Entertainment Companies and Labels. Retrieved from: https://www.kpopstarz.com/articles/294795/20200916/these-successful-kpop-idols-also-own-entertainment-companies-and-labels.htm

Do, K. (2015). K-Pop Idols: Who Trained The Longest and The Shortest? Retrieved from: https:// www.soompi.com/article/695835wpp/k-pop-idols-who-trained-the-longest-and-the-shortest

Dong, H. (2018). Sulli suffers from panic disorder, social phobia [Video]. Retrieved from: http:// www.koreatimes.co.kr/www/news/nation/2018/10/732_257093.html

Dong, S. (2018). Did Sulli delete Instagram photo over Lolita reference? Retrieved from: https:// www.koreatimes.co.kr/www/art/2018/11/732_250309.html

Dong, S. (2020). K-pop stars after glory days. Retrieved from: https://www.koreatimes.co.kr/ www/news/nation/2020/10/732_297475.html

Epstein, E., \& Joo R. (2012). Multiple Exposures: Korean Bodies and the Transnational Imagination. The Asia-Pacific Journal, 1o(33), 1-17.

Girard, R. (1987). Kozioł ofiarny (przeł. M. Goszczyńska). Łódź: Wydawnictwo Łódzkie.

Gonsalves, J. (2020). K-Pop Exposed: "Slave contracts" once ruled the industry, now fans dictate what an idol is allowed to do. Retrieved from: https://meaww.com/k-pop-exposed-slavecontracts-draconian-rules-mistreatment-label-control-fan-demands-backlash

Grazy Grace. (2018). 10 Strict Rules Kpop Artists Must Follow 그레이스. Retrieved from: https:// youtu.be/nJiCE 4 GhxwI

Haxoru. (2015). Jinnabit (Sulli’s Ex-Fansite Admin) Keeps Doing The Most! Say Sulli Hates f(x) in Recent Tweets. Retrieved from: https://omonatheydidnt.livejournal.com/16076398.html

Hazra, P. (2021). K-drama Actor Who Started As K-pop Idols And Where To Watch Them. Retrieved from: https://www.shethepeople.tv/film-theatre/k-drama-actors-k-pop-idols-iujoy-bae-suzi-yoona/

Hong, C. (2019a). Donation Made In Sulli's Name In Recognition Of Her Comments To Women's Issues. Retrieved from: https://www.soompi.com/article/1368336wpp/donation-made-insullis-name-in-recognition-of-her-commitment

Hong, C. (2019b). Sulli Included In U2's Tribute To Korean Women Of History During Their Seoul Concert. Retrieved from: https://www.soompi.com/article/1370328wpp/sulli-included-in-u2s-tribute-to-korean-women-of-history-during-their-seoul-concert

Hong, J. (2019). Cyberbullies turn their hate on dead star's ex-boyfriend. Retrieved from: http:// www.koreatimes.co.kr/www/nation/2019/10/745_277246.html

J.K. (2019). Sulli Shares How Pregnancy Rumor Started After Hospital Visit. Retrieved from: https://www.soompi.com/article/1339857wpp/sulli-shares-how-pregnancy-rumor-startedafter-hospital-visit

J.K. (2020). Insiders Question The Effectiveness Of Disabling Comments On Entertainment News; "Sulli Act" Repotedly No Longer In Talks. Retrieved from: https://www.soompi.com/article /1411495wpp/insiders-question-the-effectiveness-of-disabling-comments-on-entertainmentnews-sulli-act-reportedly-no-longer-in-talks 
Jones, J. (2014). Rumors Force Sulli To Take A Break From Performing. Retrieved from: http:// www.kdramastars.com/articles/30369/20140725/rumors-force-sulli-to-take-a-break-fromperforming.htm

Juza, M. (2015). Hejterstwo w komunikacji internetowej. Charakterystyka zjawiska, przyczyny i sposoby przeciwdziałania. Profilaktyka Społeczna i Resocjalizacja, 25, 27-50.

Kim, J. (2015). Sulli no longer f(x) member. Retrieved from: https://www.koreatimes.co.kr/www/ news/culture/2015/08/386_184442.html

Knetizen. (2019). SM ignores Sulli's request regarding her hate comments. Retrieved from: https://www.knetizen.com/sm-ignores-sullis-request-regarding-her-hate-comments/

Koreaboo. (2018a). Former Idol Reveals Why So Many K-Pop Groups Fail And Disband. Retrieved from: https://www.koreaboo.com/stories/former-idol-member-reveals-the-truth-behind-whyso-many-kpop-groups-fail-and-disband/

Koreaboo. (2018b). These Are The Main Differences Between K-Pop And American Pop. Retrieved from: https://www.koreaboo.com/lists/main-differences-kpop-american-pop-1/

Koreaboo. (2018c). 8 Idols Who Quit The Celebrity Life To Live As Normal People. Retrieved from: https://www.koreaboo.com/lists/kpop-idol-quit-celebrity-normal-life/

Koreaboo. (2018d). 6 Times Haters Bashed Sulli Because They Couldn't Handle Her Awesomeness. Retrieved from: https://www.koreaboo.com/lists/6-times-haters-bashed-sulli-because-theycouldnt-handle-her-awesomeness/

Koreaboo. (2020). Here's A Breakdown Of What A Typical Week As K-Pop Idol Trainee Would Look Like. Retrieved from: https://www.koreaboo.com/stories/heres-breakdown-typicalweek-kpop-idol-trainee-look-like/

Korea Times. (2020). Life after K-pop: From YouTube fame to solo careers, how do the stars cope when their glory days end? Retrieved from: https://www.scmp.com/lifestyle/entertainment/ article/3105491/life-after-k-pop-youtube-fame-solo-careers-how-do-stars

kpopStarz. (2020). 13 K-Pop Groups Wherein All Members Had Their Solo Debut, Solo Song, or Solo Acting Career. Retrieved from: https://www.newsbreak.com/news/2040716139725/13-kpop-groups-wherein-all-members-had-their-solo-debut-solo-song-or-solo-acting-career

Lee, S. (2016). ,SNL8’ parodizes recent celebrity scandals. Retrieved from: http://www.kpopherald.com/view.php?ud=201609251814431324912_2

Leung, S. (2012). Catching the K-Pop Wave: Globality in the Production, Distribution and Consumption of South Korean Popular Music. Retrieved from: https://digitalwindow.vassar.edu/senior_capstone/149/?utm_source=digitalwindow.vassar.edu\%2Fsenior_capstone\%2F149\&utm_medium=PDF\&utm_campaign=PDFCoverPages

Lim, J. (2019). Sulli's Law. Retrieved from: http://www.koreatimes.co.kr/www/news/nation/2019/10/352_277559.html

Lin. (2019). Netizens \& BLINKs Angry Again While Claiming Jennie Continues To Have Better Treatment Than Other BLACKPINK Members. Retrieved from: https://www.kpopmap.com/ netizens-blinks-angry-again-while-claiming-jennie-continues-to-have-better-treatment-thanother-blackpink-members/

Mark. (2017). Is Sulli a Symbol of Sexual Liberation or Internalized Oppression? Retrieved from: https://seoulbeats.com/2017/o5/is-sulli-a-symbol-of-sexual-liberation-or-internalizedoppression/

Moreau, B. (2020). Here Are 5 Korean Beauty Standards That K-Pop Idols Are Smashing. Retrieved from: https://www.koreaboo.com/lists/korean-beauty-standards-idols/

Peycheva, S. (2012). The Price of Fame in South Korea. Retrieved from: https://web.archive.org/ web/20120903001114/http:/www.toonaripost.com/2012/o8/entertainment/the-price-of-fame-in-south-korea/

Rice, L. (2019). Oscars Flashback: The tragic life and death of former Disney star Bobby Driscoll. Retrieved from: https://ew.com/oscars/2019/o1/22/bobby-driscoll-former-disney-star-oscarwinner/ 
Sayuridoll. (2016). Princess Sulli Delates Her Instagram Account. Retrieved from: https://omonatheydidnt.livejournal.com $/ 18127785 . \mathrm{html}$

SBS PopAsia HQ. (2018). How much money a K-pop idol makes (according to a former K-pop idol). Retrieved from: https://www.sbs.com.au/popasia/blog/2018/o1/29/how-much-moneyk-pop-idol-makes-according-former-k-pop-idol

Seabrook, J. (2012). Factory Girls. Cultural technology and the making of K-pop. Retrieved from: https://www.newyorker.com/magazine/2012/10/o8/factory-girls-2

Seoulspace. (2021a). How to be a K-Pop star - Top 1o Best Tips for Kpop Auditions. Retrieved from: https://seoulspace.com/how-to-be-a-kpop-star-top-10-best-tips-for-kpop-auditions/

Seoulspace. (2012b). Korean Beauty Standards Starting to Evolve for the Better. Retrieved from: https://seoulspace.com/korean-beauty-standards-starting-to-evolve-for-the-better/

Sutherland Labs. (2015). Social media and a culture of voyeurism. Retrieved from: https://www. sutherlandlabs.com/blog/social-media-and-a-culture-of-voyeurism/

Tan, L. (2019). Kpop ex-idols Youtube channels - it's a thing | campus.sg. Retrieved from: https:// www.campus.sg/kpop-ex-idol-youtube-channels-its-a-thing-campus-sg/

Upadhyay, R. (2021). Upcoming K-Pop Audition 2021 For Girls: How To Apply. Retrieved from: https://otakukart.com/upcoming-k-pop-audition-2021-for-girls/

Wamxiang. (2018). Knowing for Going Braless, Kpop Stars Sulli and Hwasa Spark Debate on Women's Freedom. Retrieved from: https://www.feedme.com.my/known-for-going-bralesskpop-stars-sulli-and-hwasa-spark-debate-on-womens-freedom/

Williamson, L. (2011). The dark side of South Korean pop music. Retrieved from: https://www. bbc.com/news/world-asia-pacific-13760064

Womack, L. (2021). 10 Weird Rules K-Pop Stars Have To Follow. Retrieved from: https://www. therichest.com/pop-culture/kpop-stars-weird-rules-follow/

Yeo, J. (2019). Kakao suspends online comments for entertainment articles after Sulli's death. Retrieved from: http://www.koreaherald.com/view.php?ud=20191025000711

Yuryunj. (2015). Korean Netizen vs International Reactions to K-Pop News. Retrieved from: https://www.soompi.com/article/696263wpp/korean-netizen-vs-international-reactions-tok-pop-news

Zielińska, I. (2004). Media, interes i panika moralna. Nowa kategoria socjologiczna i jej implikacje. Kultura i Społeczeństwo, 48(4), 161-177. 